\title{
Article
}

\section{Specific Incorporation of Polyunsaturated Fatty Acids into the sn-2 Position of Phosphatidylglycerol Accelerates Photodamage to Photosystem II under Strong Light}

\author{
Haruhiko Jimbo ${ }^{1, * \mathbb{D}}$, Koki Yuasa ${ }^{1,2,+}$, Kensuke Takagi $^{1}$, Takashi Hirashima ${ }^{1, \neq} \mathbb{D}$, Sumie Keta ${ }^{3}$, Makiko Aichi ${ }^{3}$ \\ and Hajime Wada ${ }^{1}$ \\ 1 Department of Life Sciences, Graduate School of Arts and Sciences, The University of Tokyo, Tokyo 153-8902, \\ Japan; yuasa_koki98@fra.go.jp (K.Y.); takagi-kensuke543@g.ecc.u-tokyo.ac.jp (K.T.); \\ thirashima@cc.kyoto-su.ac.jp (T.H.); hwada@g.ecc.u-tokyo.ac.jp (H.W.) \\ 2 Department of Biochemistry and Molecular Biology, Graduate School of Science and Engineering, Saitama \\ University, Saitama 338-8570, Japan \\ 3 Department of Biological Chemistry, Chubu University, Kasugai 487-8501, Japan; keta@isc.chubu.ac.jp (S.K.); \\ makiko@isc.chubu.ac.jp (M.A.) \\ * Correspondence: hjimbo@bio.c.u-tokyo.ac.jp; Tel.: +81-3-5454-6628 \\ + Present address: Fisheries Technology Institute, Japan Fisheries Research and Education Agency, \\ Hiroshima 738-8635, Japan. \\ ‡ Present address: Faculty of Life Sciences, Kyoto Sangyo University, Kyoto 603-8555, Japan.
}

Citation: Jimbo, H.; Yuasa, K.; Takagi, K.; Hirashima, T.; Keta, S.; Aichi, M.; Wada, H. Specific Incorporation of Polyunsaturated Fatty Acids into the $s n-2$ Position of Phosphatidylglycerol Accelerates Photodamage to Photosystem II under Strong Light. Int. J. Mol. Sci. 2021, 22, 10432. https://doi.org/ $10.3390 /$ ijms221910432

Academic Editors: Liangsheng Wang and Koichi Kobayashi

Received: 26 August 2021

Accepted: 21 September 2021

Published: 28 September 2021

Publisher's Note: MDPI stays neutral with regard to jurisdictional claims in published maps and institutional affiliations.

Copyright: (c) 2021 by the authors. Licensee MDPI, Basel, Switzerland. This article is an open access article distributed under the terms and conditions of the Creative Commons Attribution (CC BY) license (https:/ / creativecommons.org/licenses/by/ $4.0 /)$.
Abstract: Free fatty acids (FFAs) are generated by the reaction of lipases with membrane lipids. Generated polyunsaturated fatty acids (PUFAs) containing more than two double bonds have toxic effects in photosynthetic organisms. In the present study, we examined the effect of exogenous FFAs in the growth medium on the activity of photosystem II (PSII) under strong light in the cyanobacterium Synechocystis sp. PCC 6803 (Synechocystis). PUFAs but not monounsaturated fatty acids accelerated the rate of photodamage to PSII by inactivating electron transfer at the oxygenevolving complex. Moreover, supplemented PUFAs were specifically incorporated into the sn-2 position of phosphatidylglycerol (PG), which usually contains C16 fatty acids at the sn-2 position in Synechocystis cells. The disruption of the gene for an acyl-ACP synthetase reduced the effect of PUFAs on the photoinhibition of PSII. Thus, the specific incorporation of PUFAs into PG molecules requires acyl-ACP synthetase and leads to an unstable PSII, thereby accelerating photodamage to PSII. Our results are a breakthrough into elucidating the molecular mechanism of the toxicity of PUFAs to photosynthetic organisms.

Keywords: Synechocystis; photoinhibition; free fatty acids; phosphatidylglycerol; polyunsaturated fatty acids

\section{Introduction}

Fatty acids (FAs) are essential components consisting of membrane lipids in living cells. Free fatty acids (FFAs) are produced by lipases that hydrolyze acyl chains from membrane lipids and become substrates used for the biosynthesis of storage compounds and plant hormones as well as acylation of proteins. FFAs have a broad diversity in terms of the chain length, number, and position of double bonds with cis/trans configuration. Such a wide spectrum has different effects on photosynthetic activities, as reported in Synechocystis sp. PCC 6803 (hereafter Synechocystis) [1]. A polyunsaturated FA (PUFA), $\alpha$-linolenic acid $\left(18: 3^{\Delta 9,12,15}\right)$, increased the sensitivity of photosystem II (PSII) to lightinduced damage to photosynthesis (photoinhibition), which had toxic effects on cellular growth [1,2]. It also inhibited photosynthetic activity, and the inhibition was mediated by its incorporation into membrane lipids via the action of the acyl-acyl carrier protein 
(acyl-ACP) synthetase (AAS) [3-5]. However, the molecular mechanisms underlying the inhibitory effect of $18: 3^{\Delta 9,12,15}$ or other PUFAs on photosynthesis are still unclear.

PSII uses light energy to oxidize water molecules to extract electrons and for producing oxygen. Under strong light, excess light energy damages PSII (photodamage). The damaged PSII is repaired by a rapid repair cycle (repair) that depends on protein synthesis. The rate of PSII photodamage can be observed in the presence of inhibitors of protein synthesis such as lincomycin or chloramphenicol [6-8]. PSII photodamage has been observed for more than 50 years [9]; however, the molecular mechanism of PSII photodamage is still under investigation. The acceptor/donor side hypothesis describes how the reactive oxygen species (ROS) produced by limitation of the photosynthetic electron acceptor/donor cause PSII photodamage [10]. Further studies have shown that ROS inhibits PSII repair rather than PSII photodamage [11-13]. Several studies using inhibitors of protein synthesis revealed that the rate of photodamage is associated with light intensity but not with the rate of photosynthetic electron transport $[8,14]$. The most recent hypothesis describes PSII photodamage as occurring in two steps: (1) corruption of the oxygen-evolving complex (OEC) by the absorption of blue/UV light and (2) inactivation of D1, a reaction center of PSII, by the absorption of visible light by chlorophylls (Chls) [14,15]. Recently, visible light was also found to induce corruption of the OEC [16].

In the present study, we examined the effect of various unsaturated FFAs on the photoinhibition of PSII by using chemical biological techniques. When PUFAs were incorporated into the $s n-2$ position of PG molecules via the action of AAS, PSII complexes were destabilized and PSII was inactivated without affecting electron transfer at the reaction center of PSII. Here, we report the specific action of PUFAs on PSII photodamage, mainly by corrupting the OEC via acylation of PG with PUFAs at the $s n-2$ position.

\section{Results}

2.1. PUFAs Accelerate Photodamage by Inhibiting Electron Transfer at the Oxygen-Evolving Complex

Unsaturated FFAs induce light-inducible photodamage in PSII, as we reported previously [1]. To further investigate the effect of unsaturated FAs on photosynthesis, we examined the effect of several unsaturated FFAs containing double bonds of different numbers, at different positions and with different configurations (cis/trans) on the photoinhibition of PSII (Figure 1a). Photodamage to PSII was observed in the presence of lincomycin, an inhibitor of protein synthesis that is required for the repair of PSII (Figure 1b). As we reported previously, 18:3 $3^{\Delta 9,12,15}$, which has three cis double bonds at the $\Delta 9,12$, and 15 positions, accelerated photoinhibition and photodamage to PSII, but oleic acid $\left(18: 1^{\Delta 9}\right)$, with a cis double bond at the $\Delta 9$ position, did not (Figure 1). Other monounsaturated FAs (MUFAs), such as cis-12-octadecenoic acid (18:1 $\left.1^{\Delta 12}\right)$, containing a cis double bond at $\Delta 12$, and elaidic acid $\left(18: 1^{\Delta 9 t}\right)$, containing a trans double bond at $\Delta 9$, did not accelerate the photodamage to PSII (Figure 1b). $\gamma$-linolenic acid $\left(18: 3^{\Delta 6,9,12}\right)$ and linoleic acid $\left(18: 2^{\Delta 9,12}\right)$ induced photoinhibition and photodamage to PSII to a similar extent to that induced by 18:3 ${ }^{\Delta 9,12,15}$ (Figure 1), thus PUFAs but not cis- or trans-MUFAs induced photodamage to PSII. By contrast, under weak light, 18: $3^{\Delta 9,12,15}$ did not affect the PSII activity. We chose $18: 3^{\Delta 9,12,15}$ as a model PUFA and $18: 1^{\Delta 12}$ for MUFA for the further experiments as described below. The content of these unsaturated FAs was very low in Synechocystis cells grown without FA supplementation, and thus, it was easy to trace them after incorporation into the cells. 
(a)

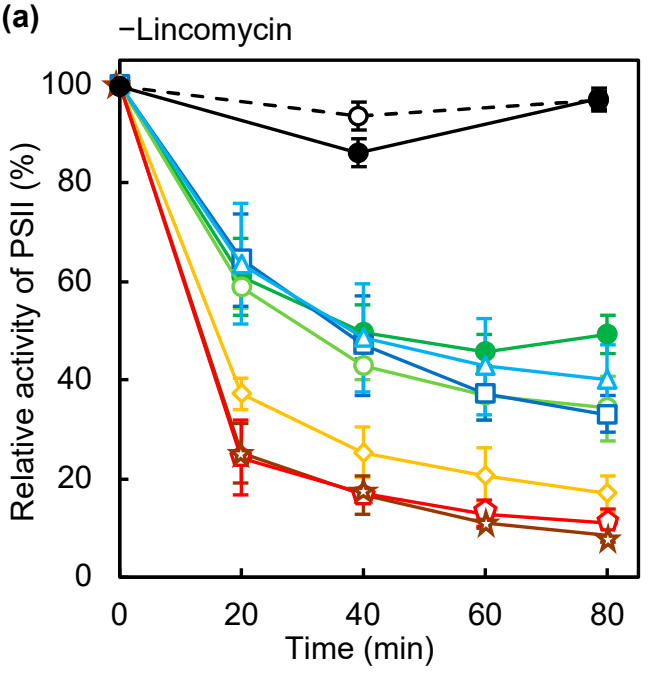

(b) +Lincomycin

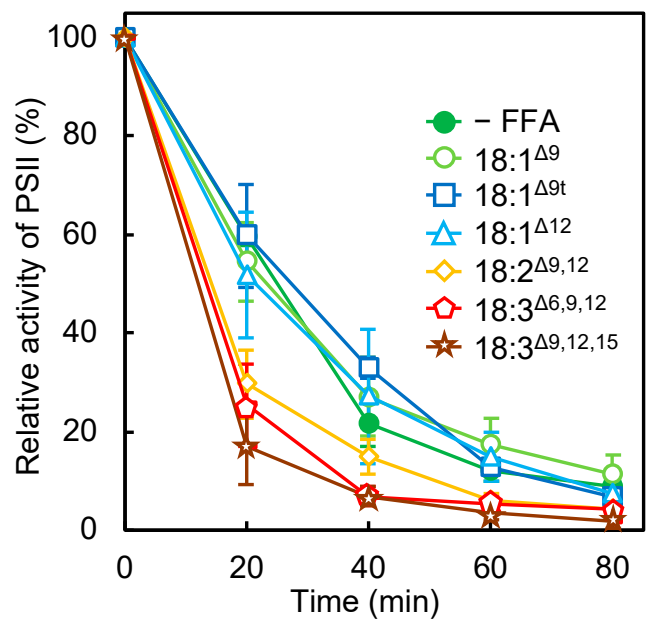

Figure 1. Effect of several C18 free fatty acids (FFAs) on the photoinhibition of PSII. Wild-type cells were incubated in the absence (filled green circles) or presence of oleic acid (18:1 ${ }^{\Delta 9}$; light green circles), elaidic acid (18:1 ${ }^{\Delta 9 t}$; blue squares), cis-12octadecenoic acids (18:1 ${ }^{\Delta 12}$; light blue triangles), linoleic acid (18:2 $2^{\Delta 9,12}$; yellow rhombuses), $\gamma$-linolenic acid (18:3 ${ }^{\Delta 6,9,12}$; red pentagons), or $\alpha$-linolenic acid $\left(18: 3^{\Delta 9,12,15}\right.$; brown stars) at $32{ }^{\circ} \mathrm{C}$ under strong light at $1500 \mu \mathrm{mol} \mathrm{photons} \mathrm{m}^{-2} \mathrm{~s}^{-1}$ under ambient aeration without (a) and with (b) lincomycin. Changes in PSII activity under weak light at $70 \mu \mathrm{mol}$ photons $\mathrm{m}^{-2} \mathrm{~s}^{-1}$ under ambient aeration in the absence (empty circles) or presence (filled circles) of $\alpha$-linolenic acid $\left(18: 3^{\Delta 9,12,15}\right.$ ) are also shown in (a). FFAs were supplemented at a final concentration of $50 \mu \mathrm{mol} \mathrm{L}^{-1}$ just before illumination. The activity of PSII was monitored in terms of the evolution of oxygen in the presence of $1 \mathrm{mmol} \mathrm{L}^{-1} 1,4$-benzoquinone as the electron acceptor. Values are the means \pm SD of three independent experiments.

According to the two-step model, photodamage to PSII can occur in two steps: (1) corruption of the OEC and (2) inactivation of electron transfer in the reaction center of PSII $[14,15]$. We examined the effect of PUFAs on the electron transfer activity of PSII by using diphenylcarbazide (DPC) and 2,6-dichlorophenolindophenol (DCIP) as an electron donor and acceptor, respectively [17]. The activity of electron transfer from $\mathrm{H}_{2} \mathrm{O}$ or DPC to DCIP in the thylakoid membranes from wild-type (WT) cells incubated with or without 18:3 $3^{\Delta 9,12,15}$ decreased under exposure to strong light for $20 \mathrm{~min}$ (Figure 2). Moreover, 18:3 $3^{\Delta 9,12,15}$ inhibited the electron transfer activity from $\mathrm{H}_{2} \mathrm{O}$ to DCIP (Figure 2a), which corresponds to the whole PSII activity and is consistent with the results obtained in Figure 1a. The electron transfer activity from DPC to DCIP, which corresponds to the electron transfer within D1/D2, decreased at a similar rate to that in the thylakoid membranes from cells incubated without 18:3 $3^{\Delta 9,12,15}$ (Figure 2b). When incubated with 18:1 ${ }^{\Delta 12}$, the electron transfer activity from $\mathrm{H}_{2} \mathrm{O}$ or DPC to DCIP decreased at a similar rate to that in thylakoid membranes from cells incubated without 18:1 ${ }^{\Delta 12}$ (Figure 2). Therefore, $18: 3^{\Delta 9,12,15}$ accelerated the corruption of the OEC but not inactivation of electron transfer within the reaction center of PSII. 
(a)

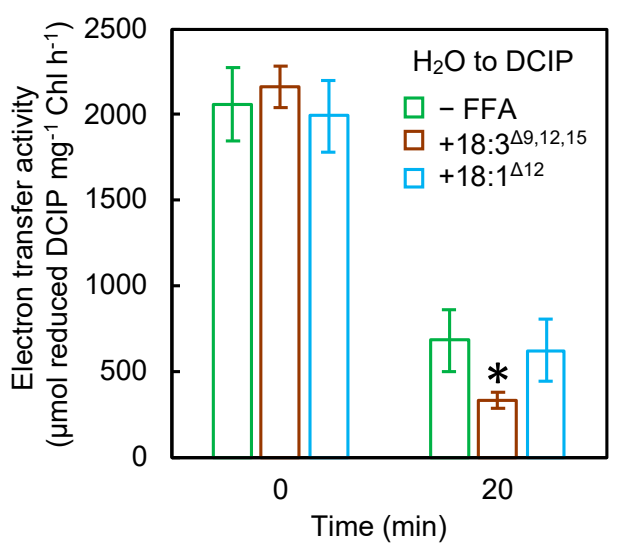

(b)

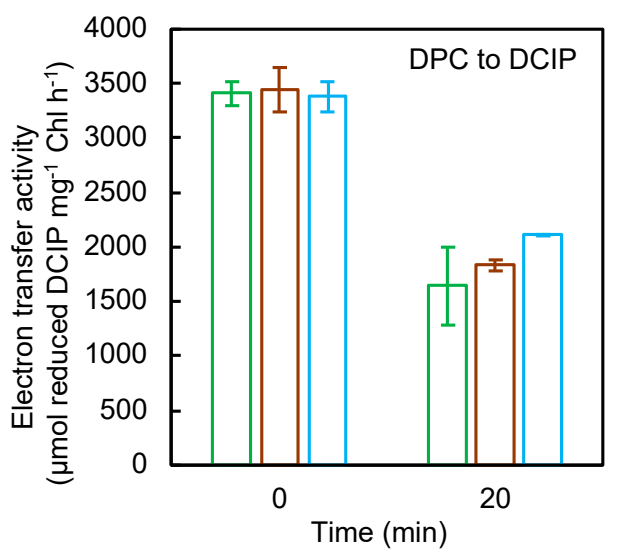

Figure 2. Effect of unsaturated C18 FFAs on electron transfer in PSII. Thylakoid membranes were prepared from cells exposed to strong light at $1500 \mu \mathrm{mol}$ photons $\mathrm{m}^{-2} \mathrm{~s}^{-1}$ at $32{ }^{\circ} \mathrm{C}$ without (green bars) or with 18:3 $3^{\Delta 9,12,15}$ (brown bars) or 18:1 ${ }^{\Delta 12}$ (light blue bars) at a final concentration of $50 \mu \mathrm{mol} \mathrm{L}{ }^{-1}$. The electron transfer activity from $\mathrm{H}_{2} \mathrm{O}$ (a) or diphenylcarbazide (DPC) (b) to 2,6-dichlorophenolindophenol (DCIP) was calculated by changes in absorbance at $580 \mathrm{~nm}$ due to the reduction of DCIP at $32{ }^{\circ} \mathrm{C}$ under strong light at $1500 \mu \mathrm{mol}$ photons $\mathrm{m}^{-2} \mathrm{~s}^{-1}$. To measure the electron transfer rates from DPC to DCIP, the oxygen-evolving complex (OEC) in thylakoid samples was disrupted by incubation with $5 \mathrm{mM} \mathrm{NH}_{2} \mathrm{OH}$ for $5 \mathrm{~min}$ on ice. Values are the means \pm SD (bars) of three independent experiments. Asterisks indicate statistically significant differences $\left({ }^{*} p<0.05\right.$; Student's $t$-test).

\section{2. $18: 3^{\Delta 9,12,15}$ Destabilizes Photosynthetic Complexes under Strong Light}

To investigate the effect of $18: 3^{\Delta 9,12,15}$ on photosynthetic complexes under strong light, we analyzed protein complexes in thylakoid membranes from cells treated with $50 \mu \mathrm{mol} \mathrm{L}{ }^{-1} 18: 3^{\Delta 9,12,15}$ under strong light (Figure 3). In cells treated without 18:3 $3^{\Delta 9,12,15}$, exposure to strong light slightly decreased the amount of PSII dimer and PSI trimer, and increased PSI and PSII monomers (Figure 3). By contrast, in cells incubated with 18:3 $3^{\Delta 9,12,15}$ under strong light, mega-complexes and the amount of PSI trimer and PSII dimer and monomer complexes decreased greatly, and the amount of PSI monomer and CP43-less PSII monomer complexes (RC47) increased (Figure 3). Therefore, 18:3 $3^{\Delta 9,12,15}$ destabilized and dissociated photosystem complexes. However, 18:1 $1^{\Delta 12}$ did not have a significant effect on the photosystem complexes under strong light (Figure 3). Several lipid molecules located between protein subunits of the photosystems function as glue to stabilize the tertiary structures [18]. Thus, the incorporation of PUFAs into membrane lipids might affect the stability of protein complexes in the thylakoid membrane, which would lead to disassembly and inactivation of the PSII complexes.

\subsection{FFAs Are Incorporated into the sn-2 Position of PG Molecules by the Action of AAS under} Strong Light

To investigate the incorporation of $18: 3^{\Delta 9,12,15}$ into membrane lipids, we analyzed the FA composition of membrane lipids from cells incubated with $50 \mu \mathrm{mol} \mathrm{L}^{-1} 18: 3^{\Delta 9,12,15}$ under strong (Figure 4a) or weak light (Figure 4b). Because Synechocystis cells synthesize only a minor amount of $18: 3^{\Delta 9,12,15}$ at $32^{\circ} \mathrm{C}$ [20], its presence in membrane lipids was mostly due to the incorporation of exogeneous $18: 3^{\Delta 9,12,15}$ in the culture medium into membrane lipids. Under strong light conditions, 18: $3^{\Delta 9,12,15}$ was mainly detected in PG, so exogeneous $18: 3^{\Delta 9,12,15}$ in the culture medium was mainly incorporated into PG. Under strong light, more than $18 \mathrm{~mol} \%$ of the total FAs in PG was replaced with 18:3 $3^{\Delta 9,12,15}$ during exposure to strong light for $20 \mathrm{~min}$ (Figure 4a). Although 18:3 $3^{\Delta 9,12,15}$ was also incorporated into other lipids, such as monogalactosyldiacylglycerol (MGDG), sulfoquinovosyldiacylglycerol (SQDG), and digalactosyldiacylglycerol (DGDG), the proportions were very low: up to $2 \mathrm{~mol} \%$ after $20 \mathrm{~min}$ of incubation (Figure $4 \mathrm{a}$ ). Under weak light, a little 18:3 $3^{\Delta 9,12,15}$ was incorporated into the membrane lipids without any specificity (Figure $4 b$ ). 


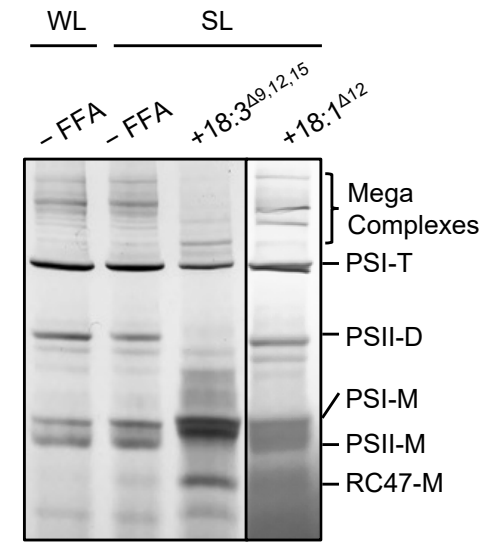

Figure 3. Effect of unsaturated C18 FFAs on photosynthetic complexes. Protein complexes in thylakoid membranes from cells incubated without (-FFA) or with $50 \mu \mathrm{mol} \mathrm{L}{ }^{-1} 18: 3^{\Delta 9,12,15}$ or 18:1 $1^{\Delta 12}$ under weak light at $70 \mu \mathrm{mol}$ photons $\mathrm{m}^{-2} \mathrm{~s}^{-1}$ (WL) or strong light at $1500 \mu \mathrm{mol}$ photons $\mathrm{m}^{-2} \mathrm{~s}^{-1}$ (SL) for $20 \mathrm{~min}$ were solubilized by $1 \%(w / v) n$-dodecyl- $\beta$-D-maltoside and separated by Blue-Native polyacrylamide gel electrophoresis. Bands on the gels were visualized by washing out excess Coomassie Brilliant Blue G-250 with distilled water. Bands for the photosynthetic complexes are identified as described previously [19]. PSI-T, Photosystem I trimer; PSII-D, Photosystem II dimer; PSI-M, Photosystem I monomer; PSII-M, Photosystem II monomer; RC47-M, CP43-less Photosystem II monomer.

(a)

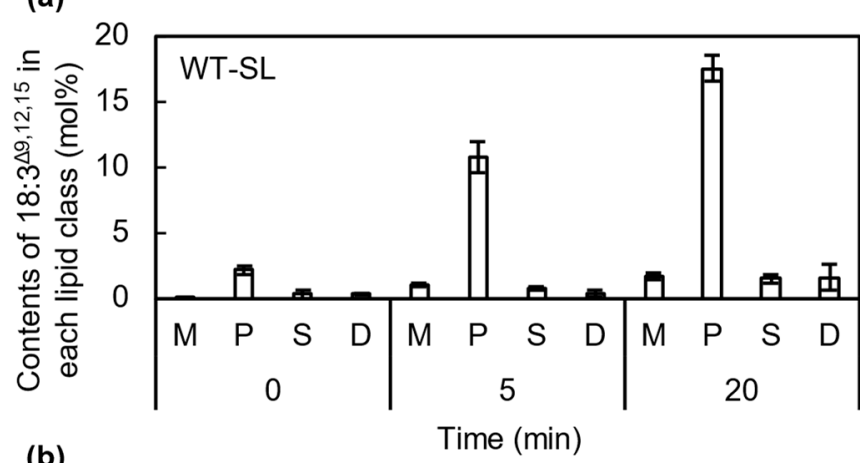

(b)

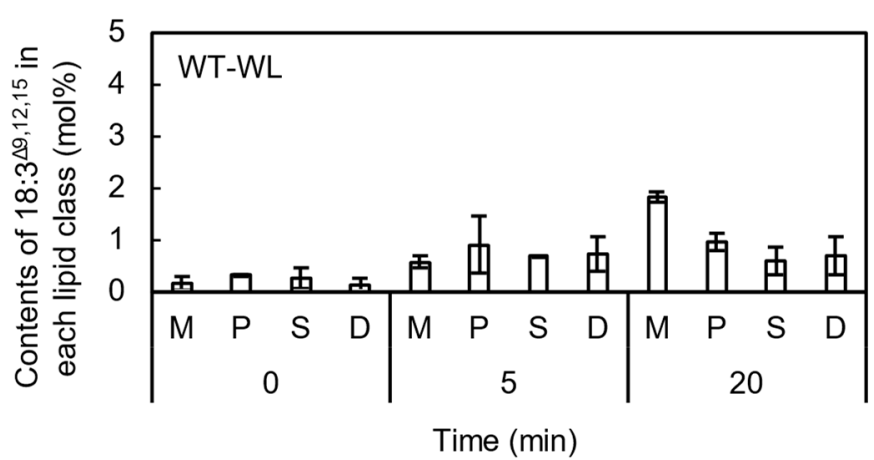

(c)

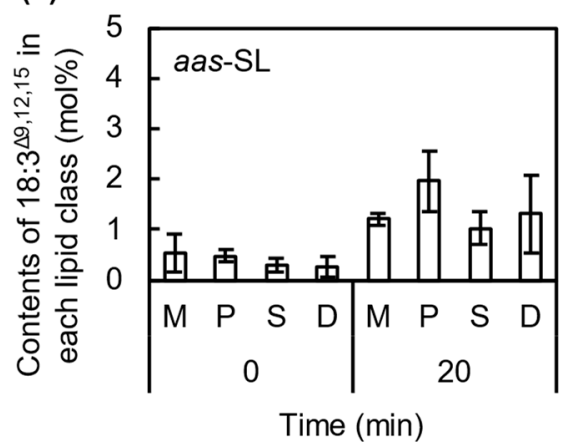

(d)

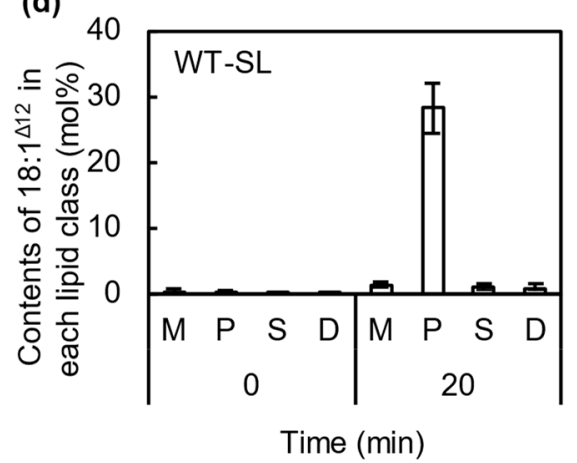

Figure 4. Specific incorporation of unsaturated C18 fatty acids into phosphatidylglycerol (PG) molecules via acyl-ACP synthase (AAS). The content of 18:3 $3^{\Delta 9,12,15}$ incorporated into membrane lipids in wild-type (a) or aas cells (c) under strong light (SL) at $1500 \mu \mathrm{mol}$ photons $\mathrm{m}^{-2} \mathrm{~s}^{-1}$ or weak light (WL) at $70 \mu \mathrm{mol}$ photons $\mathrm{m}^{-2} \mathrm{~s}^{-1}$ (b) was analyzed by thinlayer chromatography (TLC) and gas chromatography (GC). M, MGDG; P, PG; S, SQDG; D, DGDG. Content of 18:1 ${ }^{\Delta 12}$ incorporated into the membrane lipids under SL at $1500 \mu \mathrm{mol}$ photons $\mathrm{m}^{-2} \mathrm{~s}^{-1}$ for $20 \mathrm{~min}$ was also analyzed by TLC and GC (d). Values are the means \pm SD (bars) of three independent experiments. 
To check whether AAS is involved in the incorporation of 18:3 $3^{\Delta 9,12,15}$ into PG under strong light, we determined the content of $18: 3^{\Delta 9,12,15}$ in membrane lipids in aas mutant cells generated by insertion of the kanamycin-resistance gene cassette in the middle of the gene (Figure 5). When the mutant cells were incubated with $18: 3^{\Delta 9,12,15}$ under strong light for $20 \mathrm{~min}$, the specific incorporation of 18:3 $3^{\Delta 9,12,15}$ into PG was much reduced (Figure 4c). We also checked the incorporation of $18: 1^{\Delta 12}$, which did not have any effects on PSII photoinhibition (Figure 1a). Synechocystis cells do not contain 18:1 ${ }^{\Delta 12}$ because a double bond at the $\Delta 12$ position is not introduced by the $\Delta 12$ desaturase before its introduction to the $\Delta 9$ position by $\Delta 9$ desaturase [21]. Therefore, its presence in membrane lipids indicates the incorporation of exogeneous $18: 1^{\Delta 12}$ into membrane lipids. The $18: 1^{\Delta 12}$ was mainly detected in PG (Figure 4d), so 18:1 $1^{\Delta 12}$ is also specifically incorporated into PG.

(a)

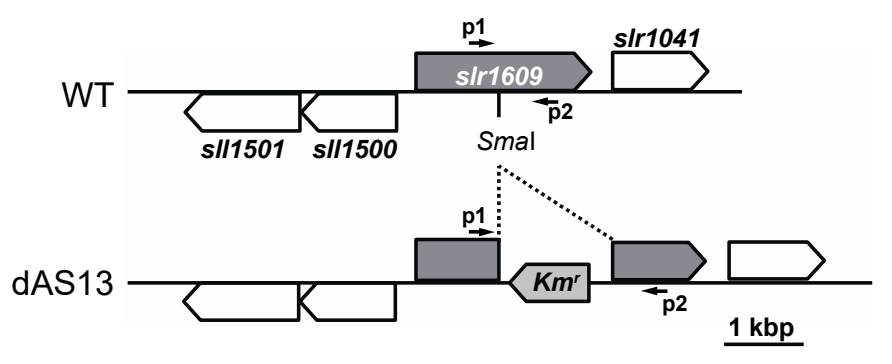

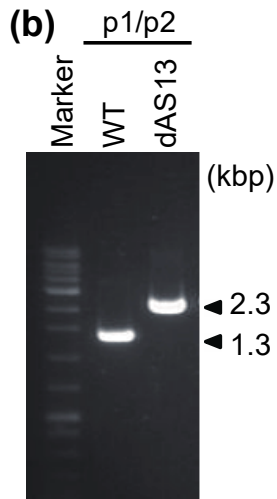

Figure 5. Construction of the aas insertional mutant (dAS13) of Synechocystis. (a) Diagrams showing the maps of the aas loci of the wild-type (WT) and the mutant (dAS13) Synechocystis. The arrows indicate the PCR primers p1 (5'-AAGGGGTGATGCTCAGCCACGG-3') and p2 (5'TTGGGTTACCACTGGTCGTTTGAGC-3') used to screen for homozygous strains in the aas locus. The primers amplify $1.3 \mathrm{~kb}$ and $2.3 \mathrm{~kb}$ DNA fragments from the Synechocystis WT strain and the dAS13 mutant, respectively. (b) PCR analysis of the aas region of WT and dAS13. The primer pair p1/p2 was used for PCR and the products were analyzed by electrophoresis on a $1.0 \%$ agarose gel.

Synechocystis PG molecules usually contain C18 FAs at the sn-1 position and C16 FAs at the $s n-2$ position (Figure $6 a)[20,22]$. We checked whether 18:1 $1^{\Delta 12}$ and $18: 3^{\Delta 9,12,15}$ were incorporated into the $s n-1$ or 2 position of PG molecules by treating purified PG from FA-treated Synechocystis cells with honey bee phospholipase $\mathrm{A}_{2}$, which specifically cleaves FAs at the $s n-2$ position of PG molecules. Most of the $18: 1^{\Delta 12}$ and $18: 3^{\Delta 9,12,15}$ was detected at the $s n-2$ position but not the $s n-1$ position of PG molecules (Figure $6 \mathrm{~b}, \mathrm{c}$ ). Therefore, 18: $1^{\Delta 12}$ and $18: 3^{\Delta 9,12,15}$ were specifically incorporated into the $s n-2$ position of PG by the action of AAS. Our results are consistent with the finding that FAs in PG molecules are remodeled in Synechocystis cells [23]. These results suggest that the incorporation of PUFAs into the $s n-2$ position of PG destabilizes photosystems, as shown in Figure 3, and enhances the photodamage to PSII.

\subsection{Disruption of the Gene for AAS Protects PSII against PUFA-Induced Photoinhibition}

Disruption of the gene for AAS induces tolerance in cells to the PUFA-induced inhibition of cellular growth [3,4]. To examine the role of AAS in PUFA-induced PSII photoinhibition, we performed similar experiments with a mutant lacking AAS. AAS was required for the incorporation of 18:3 $3^{\Delta 9,12,15}$ into membrane lipids, especially PG (Figure 4c). In wild-type cells, PSII activity dropped to $8 \%$ of the initial activity after the $80 \mathrm{~min}$ exposure to strong light in the presence of 18:3 $3^{\Delta 9,12,15}$ (Figure 1a). AAS mutant cells had $46 \%$ PSII activity in the same time (Figure 7a), indicating that the lack of AAS reduced the effect of 18: $3^{\Delta 9,12,15}$ on PSII photoinhibition or photodamage (Figure 7). Therefore, the incorporation of PUFAs into PG mediated by the action of AAS accelerates photodamage to PSII. In Syne- 
chococcus elongatus PCC 7942, the lack of AAS accelerated the photoinhibition of PSII [24]. A mutant lacking AAS had $42 \%$ of the initial PSII activity after 80 min of exposure to strong light, whereas wild-type cells retained $50 \%$ under the same conditions (Figures 1a and 7a). Thus, the lack of AAS in Synechocystis slightly accelerated the photoinhibition of PSII as well. However, the effect was smaller than that observed in Synechococcus elongatus PCC 7942 under these conditions.

(a)

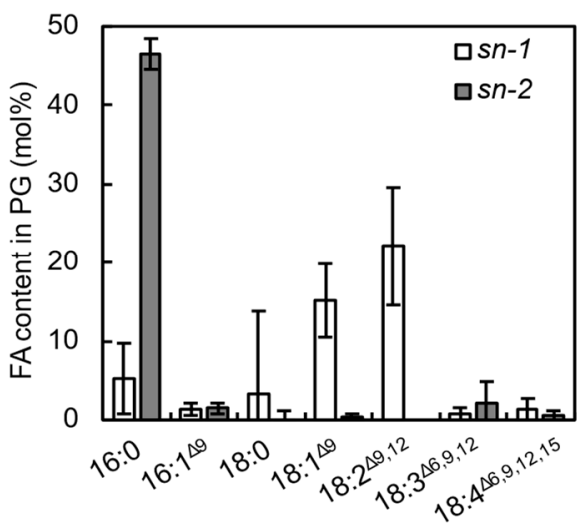

(b)

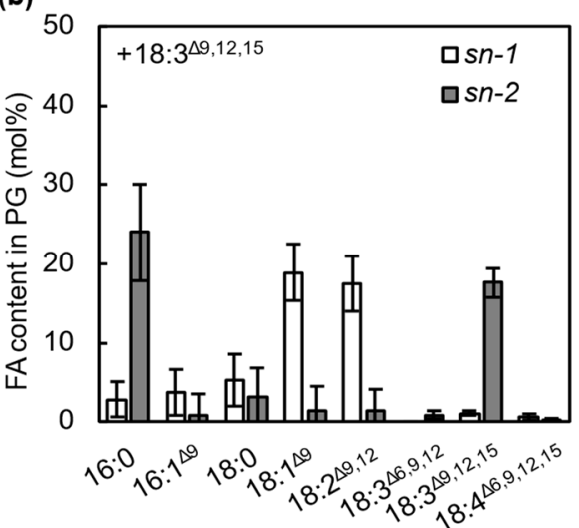

(c)

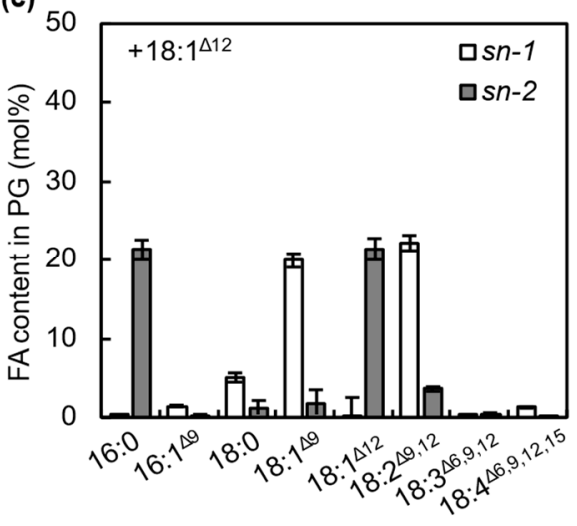

Figure 6. Distribution of incorporated unsaturated C18 FAs in PG molecules. PG molecules prepared from cells incubated without FA (a) and with $50 \mu \mathrm{mol} \mathrm{L}{ }^{-1} 18: 3^{\Delta 9,12,15}$ (b) or 18:1 ${ }^{\Delta 9}$ (c) under strong light at $1500 \mu \mathrm{mol}$ photons $\mathrm{m}^{-2} \mathrm{~s}^{-1}$ for 20 min were treated with honey bee phospholipase $A_{2}$, and the resulting 1-acyl-lysoPGs were analyzed by thin-layer chromatography and gas chromatography to determine the composition of fatty acids at the sn-1 position of PG. The composition of fatty acids at the $s n-2$ position was calculated by subtracting the fatty acid composition at the $s n-1$ position from the total fatty acid composition. Values are the means \pm SD (bars) of three independent experiments.

(a)

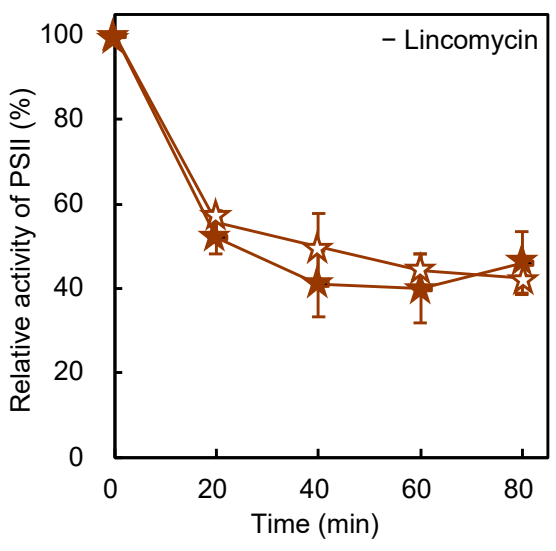

(b)

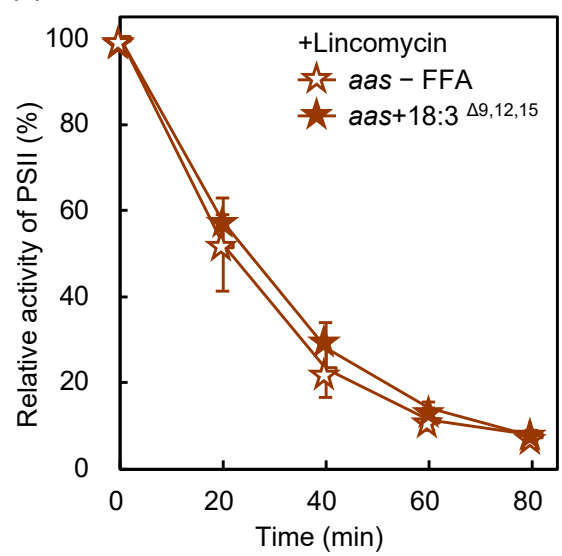

Figure 7. Effect of $18: 3^{\Delta 9,12,15}$ on the photoinhibition of PSII in an AAS-lacking mutant. aas cells in the absence (brown empty stars) or presence (brown filled stars) of $50 \mu \mathrm{mol} \mathrm{L}^{-1} 18: 3^{\Delta 9,12,15}$ were incubated at $32{ }^{\circ} \mathrm{C}$ under light at $1500 \mu \mathrm{mol}$ photons $\mathrm{m}^{-2} \mathrm{~s}^{-1}$ with ambient aeration in the absence (a) and presence (b) of lincomycin. The 18:3 $3^{\Delta 9,12,15}$ was supplemented at a final concentration of $50 \mu \mathrm{mol} \mathrm{L}{ }^{-1}$ just before the onset of illumination. The activity of PSII was monitored in terms of the evolution of oxygen in the presence of $1 \mathrm{mmol} \mathrm{L}^{-1}$,4-benzoquinone as the electron acceptor. Values are the means $\pm \mathrm{SD}$ (bars) of three independent experiments.

\section{Discussion}

\subsection{Effect of PUFAs on Photodamage to PSII}

In the present study, the specific incorporation of $18: 3^{\Delta 9,12,15}$ into the $s n-2$ position of PG molecules increased the sensitivity of PSII to photodamage by destabilizing the PSII complexes. A mutant of Synechocystis lacking two lysophosphatidic acid acyltransferases 
(LPAATs) contained a high amount of C18 FAs at the sn-2 position in all membrane lipids and shows increased PSII sensitivity to strong light as compared with WT cells [25]. Hence, C16 FAs at the $s n-2$ position of membrane lipids are important. Our results also indicated the importance of C16 FAs at the sn-2 position of PG. A marine cyanobacterium, Synechococcus sp. PCC 7002 (hereafter Synechococcus), that lacked a $\Delta 6$ desaturase showed extreme sensitivity to PUFAs [2]. A transgenic strain of Synechococcus overexpressing desD for $\Delta 6$ desaturase (DesD) from Synechocystis generated 18:3 $3^{\Delta 6,9,12}$ and $18: 4^{\Delta 6,9,12,15}$, and grew better than the WT [26]. Synechocystis DesD introduces a double bond into fatty acids bound to galactolipids rather than those bound to SQDG and PG [27,28]; thus, the severe toxicity of PUFAs for Synechococcus might be due to the incorporation of PUFAs into PG molecules but not galactolipids. PG has crucial roles in the function and maintenance of PSII [29-32]. PG is also required for the oligomerization of both the PSI and PSII complexes [33,34] and for the binding of extrinsic proteins stabilizing the OEC in PSII [35]. More than $30 \mathrm{~mol} \%$ of the total PG in the thylakoid membranes is located in the photosystems [36]. Therefore, unusual PG molecules containing PUFAs at the $s n-2$ position might specifically disorder the photosystems, especially the PSII complexes, with the resulting inactivation of PSII.

In bacteria, PG is used as a substrate for the lipidation of lipoproteins [37]. In cyanobacteria, several lumenal proteins such as CyanoP and CyanoQ, homologs of PsbP and PsbQ in land plants, are modified by diacylglycerol and palmitate [38]. CyanoP is required for stabilizing the OEC [39], and a lack of CyanoQ protein destabilizes PSII [40]. These observations suggest that unusual PG containing PUFAs at the $s n-2$ position becomes a substrate for lipidation of these lipoproteins, which might affect the stability of the OEC. A recent study by Knoppová et al. revealed that a PSII assembly factor, Ycf48, was lipidated by PG [41]. Therefore, the unstable PSII complex in the presence of PUFAs shown in Figure 3 might be due to the lipidation of Ycf48 by the unusual PG molecules.

\subsection{Incorporation of PUFAs into PG}

We showed that the effect of PUFAs on photosynthesis depends on the specific incorporation of PUFAs into the $s n-2$ position of PG molecules, which is mediated by AAS. Synechocystis AAS reacts nonspecifically with FFAs to synthesize acyl-ACPs in vitro [5]. These findings suggest that Synechocystis has a phospholipase $A_{2}$ that synthesizes 1-acyllysoPG (lysoPG) by digesting an acyl group at the sn-2 position of PG, and that a lysoPG acyltransferase (LPGAT) transfers PUFAs into the $s n-2$ position of 1-acyl-lysoPG from ACP-attached PUFAs. Weier et al. (2005) identified an LPGAT that transferred both the C16- and C18-acyl groups from acyl-ACP but not acyl-CoA to lysoPG [42]. Therefore, this lysoPG acyltransferase might be responsible for the specific incorporation of PUFAs into the $s n-2$ position of PG molecules. However, tolerance to PUFAs in the mutant lacking LPGAT has not been investigated. Synechocystis has a phospholipase encoded by sll1969 [43], which suggests that lysoPG is synthesized by the phospholipase in Synechocystis cells. Further biochemical analysis of the phospholipase is needed to investigate whether this phospholipase is involved in the synthesis of 1-acyl-lysoPG. Synechococcus elongatus PCC 7942, a mutant lacking AAS, produced more palmitic acid (16:0) and lyso-lipids under strong light [24]. This finding supports our result that the specific incorporation of PUFAs into PG molecules was accelerated under strong light.

AAS is broadly conserved among oxygenic photosynthetic organisms such as cyanobacteria and land plants [5]. PUFAs are toxic to other photosynthetic organisms as well [44], so the uptake of PUFAs into membrane lipids mediated by the action of AAS might cause a universal effect of PUFAs in photosynthetic organisms.

In plants, PG in the chloroplasts is exclusively synthesized inside the chloroplasts by the plastid pathway, which results in PG molecules containing 16:0 or $\Delta 3$-trans-hexadecenoic acid $\left(16: 1^{\Delta 3 t}\right)$ at the $s n-2$ position owing to the substrate specificity of LPAAT $[45,46]$ and the desaturation catalyzed by desaturase (FAD4) [47] in the chloroplasts. However, glycolipids in the chloroplasts, such as MGDG, DGDG, and SQDG, are synthesized not only by the plastid pathway but also the endoplasmic reticulum (ER) pathway $[48,49]$. In the ER 
pathway, FAs synthesized in the chloroplasts are exported to the cytosol and used for the synthesis of phospholipids in the ER, then some synthesized phospholipids in the ER are transferred to the chloroplasts and used for the synthesis of glycolipids. The glycolipids synthesized through the ER pathway contain C18 PUFAs at the sn-2 position owing to the substrate specificity of LPAAT and the action of desaturases (FAD2 and FAD3) in the ER [50-52]. Our results suggest that PG needs to be synthesized by the plastid pathway to avoid the synthesis of PG molecules containing PUFAs at the $s n-2$ position because such PG molecules destabilize the PSII complex and accelerate the photoinhibition of PSII.

\section{Materials and Methods}

\subsection{Strains and Culture Conditions}

Cells of glucose-tolerant Synechocystis GT-I as WT cells were grown photoautotrophically in BG-11 medium at $32{ }^{\circ} \mathrm{C}$, as described in [1]. Cells in the culture with an optical density at $730 \mathrm{~nm}$ of $1.0 \pm 0.1$ (about $3.6 \mu \mathrm{g} \mathrm{mL}^{-1} \mathrm{Chl} a$ ) were used for the assays. Generation of a mutant lacking AAS was as described in [4].

\subsection{Targeted Inactivation of aas in Synechocystis}

The aas gene (slr1609) of Synechocystis was amplified by PCR using TaKaRa LA Taq DNA polymerase (TAKARA BIO INC., Japan) and the primer pair a1 (5'-ACGCTTTGGTGA TGAACACTGG-3')/a2 (5'-TTGGCGTAGGGGAATGGCT-3'). The amplified DNA fragment was cloned into the pGEM-T easy vector (Promega, Madison, WI, USA). A 1.0-kb DNA fragment carrying the nptI kanamycin resistance gene was excised from the plasmid pRL250 [53] and ligated into the SmaI recognition site in the cloned aas gene. The resultant plasmid was used to transform the wild-type Synechocystis cells through homologous recombination into the kanamycin resistance type. After three rounds of streak purification of single colonies, the absence of the wild-type aas copy in selected colonies was confirmed by PCR. The resulting mutant, which carried an insertionally inactivated aas gene, was named dAS13 (Figure S1).

\subsection{Photosynthetic Activity of PSII}

PSII activity was measured by oxygen evolution from PSII in the presence of $1 \mathrm{mM} 1,4-$ benzoquinone (BQ) and $1 \mathrm{mM} \mathrm{K}_{3} \mathrm{Fe}(\mathrm{CN})_{6}$, as described in [1]. For the analysis of photoinhibition of PSII, cells in the culture were exposed to strong light at $1500 \mu \mathrm{mol}$ photons $\mathrm{m}^{-2} \mathrm{~s}^{-1}$ at $32{ }^{\circ} \mathrm{C}$ under ambient aeration. For assaying photodamage, the cell culture was supplemented with $200 \mu \mathrm{g} \mathrm{mL}^{-1}$ lincomycin before illumination. FFA compounds purchased from FujiFilm Wako (Tokyo, Japan) and Tokyo Chemical Industry (Tokyo, Japan) were added to the cell culture just before illumination.

To determine the electron transfer in PSII, we measured the rate of the photoreduction of DCIP, which accepts electrons from $\mathrm{Q}_{\mathrm{B}}$, with isolated thylakoid membranes in the absence or presence of diphenylcarbazide (DPC), an electron donor to a tyrosine $\mathrm{Z}$ in PSII. Electron transfer rates from $\mathrm{H}_{2} \mathrm{O}$ or DPC to 2,6-dichlorophenolindophenol (DCIP) were measured as described in [17] with some modifications. Thylakoid membranes were isolated from cells incubated under strong light at $1500 \mu \mathrm{mol}$ photons $\mathrm{m}^{-2} \mathrm{~s}^{-1}$ for $20 \mathrm{~min}$ with or without $50 \mu \mathrm{mol} \mathrm{L}{ }^{-1} 18: 3^{\Delta 9,12,15}$ or $18: 1^{\Delta 12}$, then the cells were disrupted by bead-beating in Solution $8\left(0.4 \mathrm{~mol} \mathrm{~L}^{-1}\right.$ sucrose, $2 \mathrm{mmol} \mathrm{L}^{-1} \mathrm{MgCl}_{2}, 5 \mathrm{mmol} \mathrm{L}^{-1} \mathrm{NaCl}$, $40 \mathrm{mmol} \mathrm{L}^{-1}$ Mes- $\mathrm{NaOH}, \mathrm{pH}$ 6.5). To measure the electron transfer rate from DPC to DCIP, thylakoid membranes were treated with $5 \mu \mathrm{mol} \mathrm{L}^{-1} \mathrm{NH}_{2} \mathrm{OH}$ for 5 min on ice. $\mathrm{NH}_{2} \mathrm{OH}-$ treated thylakoid membranes were washed twice, then resuspended in Solution 8 . The light-induced decrease in the absorbance by DCIP at $580 \mathrm{~nm}$ in the thylakoid membrane suspension $\left(5 \mu \mathrm{g} \mathrm{Chl} \mathrm{mL}{ }^{-1}\right)$ in the presence of $80 \mathrm{mmol} \mathrm{L}^{-1} \mathrm{DCIP}$ and $80 \mu \mathrm{mol} \mathrm{L}{ }^{-1}$ DPC under strong light at $1500 \mu \mathrm{mol}$ photons $\mathrm{m}^{-2} \mathrm{~s}^{-1}$ at $32{ }^{\circ} \mathrm{C}$ for 5 min was measured by spectrophotometry (V-730Bio, JASCO, Tokyo, Japan). 


\subsection{Analysis of Photosynthetic Complexes by Blue-Native Polyacrylamide Gel Electrophoresis} (PAGE)

Thylakoid membranes were isolated from WT cells disrupted by bead-beating with glass beads in Buffer A (50 mmol L ${ }^{-1}$ MES-NaOH pH 6.0, 10 mmol L ${ }^{-1} \mathrm{MgCl}_{2}, 5 \mathrm{mmol}$ $\mathrm{L}^{-1} \mathrm{CaCl}_{2}, 25 \%$ glycerol), as described in [54]. Thylakoid membranes corresponding to $8 \mu \mathrm{g} \mathrm{Chl}\left(1 \mathrm{mg} \mathrm{Chl} \mathrm{mL}^{-1}\right)$ were solubilized with $1 \%(w / v)$ n-dodecyl- $\beta$-D-maltoside ( $\beta$ DM) (Dojindo, Japan) for $20 \mathrm{~min}$ on ice. Protein complexes were separated on 4-20\% BlueNative-PAGE (ThermoFisher, Waltham, MA, USA) under a constant $5 \mathrm{~mA}$ for $14 \mathrm{~h}$ in a cold room. Excess Coomassie Brilliant Blue (CBB) G-250 was washed out with distilled water.

\subsection{Lipid Analysis}

To analyze the incorporation of 18:3 $3^{\Delta 9,12,15}$ into membrane lipids, cells were incubated with $50 \mu \mathrm{mol} \mathrm{L}^{-1} 18: 3^{\Delta 9,12,15}$ (Wako, Japan) under the same conditions as the analysis of PSII photoinhibition described above. A $5 \mathrm{~mL}$ aliquot of the cell culture was removed at the designated time and kept on ice until lipid extraction. Lipids in Synechocystis cells were extracted as described in [31]. Each membrane lipid was separated and isolated on a thin-layer chromatography (TLC) plate (TLC silica gel 60; Merck, Kenilworth, NJ, USA) developed with chloroform:methanol: $28 \% \mathrm{NH}_{4} \mathrm{OH}=65: 35: 5(v / v / v)$, and FAs binding to each sugar lipid were methyl-esterified with $\mathrm{HCl}$-methanol at $85^{\circ} \mathrm{C}$ for more than $3 \mathrm{~h}$. Since FFA is located at the same position as PG in TLC (Supplementary Figure S1), PG was methyl-esterified with $2 \mathrm{M} \mathrm{KOH}$-methanol at room temperature for $2 \mathrm{~min}$, which only methyl-esterified glycerolipids but not FFA, as described previously [55]. The obtained FA methylesters were analyzed by gas chromatography (GC) (GC-2014, Shimazu, Tokyo, Japan). To determine the content of FAs at the $s n-1$ and -2 positions of PG, PG isolated from cells treated with $50 \mu \mathrm{mol} \mathrm{L}{ }^{-1} 18: 3^{\Delta 9,12,15}$ for 20 min under strong light was treated with $0.5 \mu \mathrm{g}$ honey bee phospholipase $\mathrm{A}_{2}$ (Sigma-Aldrich, St. Louis, MO, USA) in a lipase buffer $\left(50 \mathrm{mmol} \mathrm{L}^{-1}\right.$ Tris- $\mathrm{HCl} \mathrm{pH} 7.5$ with $0.05 \%(w / v)$ Triton X-100) for $30 \mathrm{~min}$ at $37^{\circ} \mathrm{C}$. The resulting FFAs and 1-acyl-lyso-phosphatidylglycerol (LysoPG) were separated on a TLC plate developed with chloroform:acetone:methanol:acetic acid:water $=$ 50:20:10:15:5 $(v / v / v / v / v)$, and FAs in 1-acyl-lysoPG was methyl-esterified with $\mathrm{HCl}$-methanol at $85^{\circ} \mathrm{C}$ for $3 \mathrm{~h}$. The obtained FA methylesters were analyzed by GC (GC-2014, Shimadzu). FA content at the $s n-2$ position of the PG molecules was calculated by subtracting the FA content at the $s n-1$ position from the total fatty acid composition; 15:0 (5 nmol) was used as the internal control.

Supplementary Materials: Supplementary materials can be found at https://www.mdpi.com/ article/10.3390/ijms221910432/s1.

Author Contributions: H.J. designed the research and wrote the paper; H.J., K.Y. and K.T. performed most experiments; S.K. generated the aas-deficient mutant; T.H. provided technical assistance to H.J. and K.T.; M.A. and H.W. supervised the project. All authors have read and agreed to the published version of the manuscript.

Funding: This work was supported in part by the Japan Science and Technology Agency, ACT-X program (grant No. JPMJAX20B7 to H.J.), Grants-in-Aid for Scientific Research from the Japan Society for the Promotion of Science (No. 20K06701 to H.W. and No. 19K16161 to H.J.), and the JST-Mirai program from the Japan Science and Technology Agency (JST) (No. 6 JPMJMI17EE to M.A.).

Institutional Review Board Statement: Not applicable.

Informed Consent Statement: Not applicable.

Data Availability Statement: The data supporting the findings of this study are available within the article.

Conflicts of Interest: The authors declare no conflict of interest. 


\section{References}

1. Jimbo, H.; Takagi, K.; Hirashima, T.; Nishiyama, Y.; Wada, H. Long-chain saturated fatty acids, palmitic and stearic acids, enhance the repair of photosystem II. Int. J. Mol. Sci. 2020, 21, 7509. [CrossRef]

2. Ruffing, A.M.; Trahan, C.A. Biofuel toxicity and mechanisms of biofuel tolerance in three model cyanobacteria. Algal Res. 2014, 5, 121-132. [CrossRef]

3. Von Berlepsch, S.; Kunz, H.H.; Brodesser, S.; Fink, P.; Marin, K.; Flugge, U.I.; Gierth, M. The acyl-acyl carrier protein synthetase from Synechocystis sp. PCC 6803 mediates fatty acid import. Plant Physiol. 2012, 159, 606-617. [CrossRef]

4. Kojima, K.; Keta, S.; Uesaka, K.; Kato, A.; Takatani, N.; Ihara, K.; Omata, T.; Aichi, M. A simple method for isolation and construction of markerless cyanobacterial mutants defective in acyl-acyl carrier protein synthetase. Appl. Microbiol. Biotechnol. 2016, 100, 10107-10113. [CrossRef] [PubMed]

5. Kaczmarzyk, D.; Fulda, M. Fatty acid activation in cyanobacteria mediated by acyl-acyl carrier protein synthetase enables fatty acid recycling. Plant Physiol. 2010, 152, 1598-1610. [CrossRef] [PubMed]

6. Jimbo, H.; Izuhara, T.; Hihara, Y.; Hisabori, T.; Nishiyama, Y. Light-inducible expression of translation factor EF-Tu during acclimation to strong light enhances the repair of photosystem II. Proc. Natl. Acad. Sci. USA 2019, 116, 21268-21273. [CrossRef] [PubMed]

7. Moon, B.Y.; Higashi, S.; Gombos, Z.; Murata, N. Unsaturation of the membrane lipids of chloroplasts stabilizes the photosynthetic machinery against low-temperature photoinhibition in transgenic tobacco plants. Proc. Natl. Acad. Sci. USA 1995, 92, 6219-6223. [CrossRef] [PubMed]

8. Tyystjarvi, E.; Aro, E.M. The rate constant of photoinhibition, measured in lincomycin-treated leaves, is directly proportional to light intensity. Proc. Natl. Acad. Sci. USA 1996, 93, 2213-2218. [CrossRef] [PubMed]

9. Kok, B.; Businger, J.A. Kinetics of photosynthesis and photo-inhibition. Nature 1956, 177, 135-136. [CrossRef]

10. Vass, I. Molecular mechanisms of photodamage in the Photosystem II complex. Biochim. Biophys. Acta 2012, 1817, 209-217. [CrossRef]

11. Kusama, Y.; Inoue, S.; Jimbo, H.; Takaichi, S.; Sonoike, K.; Hihara, Y.; Nishiyama, Y. Zeaxanthin and echinenone protect the repair of photosystem II from inhibition by singlet oxygen in Synechocystis sp. PCC 6803. Plant Cell Physiol. 2015, 56, 906-916. [CrossRef] [PubMed]

12. Jimbo, H.; Yutthanasirikul, R.; Nagano, T.; Hisabori, T.; Hihara, Y.; Nishiyama, Y. Oxidation of translation factor EF-Tu inhibits the repair of photosystem II. Plant Physiol. 2018, 176, 2691-2699. [CrossRef]

13. Jimbo, H.; Noda, A.; Hayashi, H.; Nagano, T.; Yumoto, I.; Orikasa, Y.; Okuyama, H.; Nishiyama, Y. Expression of a highly active catalase VktA in the cyanobacterium Synechococcus elongatus PCC 7942 alleviates the photoinhibition of photosystem II. Photosynth. Res. 2013, 117, 509-515. [CrossRef] [PubMed]

14. Hakala, M.; Tuominen, I.; Keranen, M.; Tyystjarvi, T.; Tyystjarvi, E. Evidence for the role of the oxygen-evolving manganese complex in photoinhibition of photosystem II. Biochim. Biophys. Acta 2005, 1706, 68-80. [CrossRef] [PubMed]

15. Ohnishi, N.; Allakhverdiev, S.I.; Takahashi, S.; Higashi, S.; Watanabe, M.; Nishiyama, Y.; Murata, N. Two-step mechanism of photodamage to photosystem II: Step 1 occurs at the oxygen-evolving complex and step 2 occurs at the photochemical reaction center. Biochemistry 2005, 44, 8494-8499. [CrossRef]

16. Zavafer, A.; Cheah, M.H.; Hillier, W.; Chow, W.S.; Takahashi, S. Photodamage to the oxygen evolving complex of photosystem II by visible light. Sci. Rep. 2015, 5, 16363. [CrossRef]

17. Ohnishi, N.; Kashino, Y.; Satoh, K.; Ozawa, S.; Takahashi, Y. Chloroplast-encoded polypeptide PsbT is involved in the repair of primary electron acceptor QA of photosystem II during photoinhibition in Chlamydomonas reinhardtii. J. Biol. Chem. 2007, 282, 7107-7115. [CrossRef]

18. Umena, Y.; Kawakami, K.; Shen, J.R.; Kamiya, N. Crystal structure of oxygen-evolving photosystem II at a resolution of 1.9 A. Nature 2011, 473, 55-60. [CrossRef]

19. Endo, K.; Kobayashi, K.; Wang, H.T.; Chu, H.A.; Shen, J.R.; Wada, H. Site-directed mutagenesis of two amino acid residues in cytochrome b559 $\alpha$ subunit that interact with a phosphatidylglycerol molecule (PG772) induces quinone-dependent inhibition of photosystem II activity. Photosynth. Res. 2018, 139, 267-279. [CrossRef]

20. Wada, H.; Murata, N. Temperature-induced changes in the fatty acid composition of the cyanobacterium, Synechocystis PCC6803. Plant Physiol. 1990, 92, 1062-1069. [CrossRef]

21. Wada, H.; Murata, N. Synechocystis PCC 6803 mutants defective in desaturation of fatty acids. Plant Cell Physiol. 1989, 30, 971-978. [CrossRef]

22. Murata, N.; Wada, H.; Gombos, Z. Modes of fatty-acid desaturation in cyanobacteria. Plant Cell Physiol. 1992, 33, $933-941$.

23. Laczko-Dobos, H.; Frycak, P.; Ughy, B.; Domonkos, I.; Wada, H.; Prokai, L.; Gombos, Z. Remodeling of phosphatidylglycerol in Synechocystis PCC 6803. Biochim. Biophys. Acta 2010, 1801, 163-170. [CrossRef] [PubMed]

24. Takatani, N.; Use, K.; Kato, A.; Ikeda, K.; Kojima, K.; Aichi, M.; Maeda, S.; Omata, T. Essential role of acyl-ACP synthetase in acclimation of the cyanobacterium Synechococcus elongatus strain PCC 7942 to high-light conditions. Plant Cell Physiol. 2015, 56, 1608-1615. [CrossRef] [PubMed]

25. Okazaki, K.; Sato, N.; Tsuji, N.; Tsuzuki, M.; Nishida, I. The significance of C16 fatty acids in the sn-2 positions of glycerolipids in the photosynthetic growth of Synechocystis sp. PCC 6803. Plant Physiol. 2006, 141, 546-556. [CrossRef] 
26. Dong, X.; He, Q.; Peng, Z.; Yu, J.; Bian, F.; Li, Y.; Bi, Y. Production of $\gamma$-linolenic acid and stearidonic acid by Synechococcus sp. PCC7002 containing cyanobacterial fatty acid desaturase genes. Chin. J. Oceanol. Limnol. 2016, 34, 772-780. [CrossRef]

27. Murata, N.; Wada, H. Acyl-lipid desaturases and their importance in the tolerance and acclimatization to cold of cyanobacteria. Biochem. J. 1995, 308, 1-8. [CrossRef]

28. Kis, M.; Zsiros, O.; Farkas, T.; Wada, H.; Nagy, F.; Gombos, Z. Light-induced expression of fatty acid desaturase genes. Proc. Natl. Acad. Sci. USA 1998, 95, 4209-4214. [CrossRef]

29. Sakurai, I.; Hagio, M.; Gombos, Z.; Tyystjarvi, T.; Paakkarinen, V.; Aro, E.M.; Wada, H. Requirement of phosphatidylglycerol for maintenance of photosynthetic machinery. Plant Physiol. 2003, 133, 1376-1384. [CrossRef]

30. Hagio, M.; Gombos, Z.; Varkonyi, Z.; Masamoto, K.; Sato, N.; Tsuzuki, M.; Wada, H. Direct evidence for requirement of phosphatidylglycerol in photosystem II of photosynthesis. Plant Physiol. 2000, 124, 795-804. [CrossRef]

31. Jimbo, H.; Izuhara, T.; Hirashima, T.; Endo, K.; Nakamura, Y.; Wada, H. Membrane lipid remodeling is required for photosystem II function under low CO2. Plant J. 2021, 105, 245-253. [CrossRef]

32. Mizusawa, N.; Wada, H. The role of lipids in photosystem II. Biochim. Biophys. Acta 2012, 1817, 194-208. [CrossRef]

33. Domonkos, I.; Malec, P.; Sallai, A.; Kovacs, L.; Itoh, K.; Shen, G.; Ughy, B.; Bogos, B.; Sakurai, I.; Kis, M.; et al. Phosphatidylglycerol is essential for oligomerization of photosystem I reaction center. Plant Physiol. 2004, 134, 1471-1478. [CrossRef]

34. Kruse, O.; Hankamer, B.; Konczak, C.; Gerle, C.; Morris, E.; Radunz, A.; Schmid, G.H.; Barber, J. Phosphatidylglycerol is involved in the dimerization of photosystem II. J. Biol. Chem. 2000, 275, 6509-6514. [CrossRef]

35. Sakurai, I.; Mizusawa, N.; Ohashi, S.; Kobayashi, M.; Wada, H. Effects of the lack of phosphatidylglycerol on the donor side of photosystem II. Plant Physiol. 2007, 144, 1336-1346. [CrossRef]

36. Kobayashi, K.; Endo, K.; Wada, H. Specific distribution of phosphatidylglycerol to photosystem complexes in the thylakoid membrane. Front. Plant Sci. 2017, 8, 1991. [CrossRef] [PubMed]

37. Sankaran, K.; Wu, H.C. Lipid modification of bacterial prolipoprotein. Transfer of diacylglyceryl moiety from phosphatidylglycerol. J. Biol. Chem. 1994, 269, 19701-19706. [CrossRef]

38. Fagerlund, R.D.; Eaton-Rye, J.J. The lipoproteins of cyanobacterial photosystem II. J. Photochem. Photobiol. B 2011, 104, 191-203. [CrossRef]

39. Sveshnikov, D.; Funk, C.; Schroder, W.P. The PsbP-like protein (sll1418) of Synechocystis sp. PCC 6803 stabilises the donor side of Photosystem II. Photosynth. Res. 2007, 93, 101-109. [CrossRef] [PubMed]

40. Kashino, Y.; Inoue-Kashino, N.; Roose, J.L.; Pakrasi, H.B. Absence of the PsbQ protein results in destabilization of the PsbV protein and decreased oxygen evolution activity in cyanobacterial photosystem II. J. Biol. Chem. 2006, 281, 20834-20841. [CrossRef] [PubMed]

41. Knoppová, J.; Yu, J.; Janouškovec, J.; Halada, P.; Nixon, P.J.; Whitelegge, J.P.; Komenda, J. The Photosystem II assembly factor Ycf48 from the cyanobacterium Synechocystis sp. PCC 6803 is lipidated using an atypical lipobox sequence. Int. J. Mol. Sci. 2021, 22, 3733. [CrossRef]

42. Weier, D.; Muller, C.; Gaspers, C.; Frentzen, M. Characterisation of acyltransferases from Synechocystis sp. PCC 6803. Biochem. Biophys. Res. Commun. 2005, 334, 1127-1134. [CrossRef] [PubMed]

43. Eungrasamee, K.; Miao, R.; Incharoensakdi, A.; Lindblad, P.; Jantaro, S. Improved lipid production via fatty acid biosynthesis and free fatty acid recycling in engineered Synechocystis sp. PCC 6803. Biotechnol. Biofuels 2019, 12, 8. [CrossRef] [PubMed]

44. Qian, H.; Xu, J.; Lu, T.; Zhang, Q.; Qu, Q.; Yang, Z.; Pan, X. Responses of unicellular alga Chlorella pyrenoidosa to allelochemical linoleic acid. Sci. Total Environ. 2018, 625, 1415-1422. [CrossRef] [PubMed]

45. Kim, H.U.; Huang, A.H. Plastid lysophosphatidyl acyltransferase is essential for embryo development in Arabidopsis. Plant Physiol. 2004, 134, 1206-1216. [CrossRef]

46. Yu, B.; Wakao, S.; Fan, J.; Benning, C. Loss of plastidic lysophosphatidic acid acyltransferase causes embryo-lethality in Arabidopsis. Plant Cell Physiol. 2004, 45, 503-510. [CrossRef] [PubMed]

47. Gao, J.; Ajjawi, I.; Manoli, A.; Sawin, A.; Xu, C.; Froehlich, J.E.; Last, R.L.; Benning, C. Fatty Acid Desaturase4 of Arabidopsis encodes a protein distinct from characterized fatty acid desaturases. Plant J. 2009, 60, 832-839. [CrossRef] [PubMed]

48. Browse, J.; Warwick, N.; Somerville, C.R.; Slack, C.R. Fluxes through the prokaryotic and eukaryotic pathways of lipid synthesis in the '16:3' plant Arabidopsis thaliana. Biochem. J. 1986, 235, 25-31. [CrossRef] [PubMed]

49. Wang, Z.; Benning, C. Chloroplast lipid synthesis and lipid trafficking through ER-plastid membrane contact sites. Biochem. Soc. Trans. 2012, 40, 457-463. [CrossRef] [PubMed]

50. Arondel, V.; Lemieux, B.; Hwang, I.; Gibson, S.; Goodman, H.M.; Somerville, C.R. Map-based cloning of a gene controlling omega-3 fatty acid desaturation in Arabidopsis. Science 1992, 258, 1353-1355. [CrossRef]

51. Okuley, J.; Lightner, J.; Feldmann, K.; Yadav, N.; Lark, E.; Browse, J. Arabidopsis FAD2 gene encodes the enzyme that is essential for polyunsaturated lipid synthesis. Plant Cell 1994, 6, 147-158. [CrossRef] [PubMed]

52. Kim, H.U.; Li, Y.; Huang, A.H. Ubiquitous and endoplasmic reticulum-located lysophosphatidyl acyltransferase, LPAT2, is essential for female but not male gametophyte development in Arabidopsis. Plant Cell 2005, 17, 1073-1089. [CrossRef] [PubMed] 
53. Cai, Y.P.; Wolk, C.P. Use of a conditionally lethal gene in Anabaena sp. strain PCC 7120 to select for double recombinants and to entrap insertion sequences. J. Bacteriol. 1990, 172, 3138-3145. [CrossRef]

54. Bricker, T.M.; Morvant, J.; Masri, N.; Sutton, H.M.; Frankel, L.K. Isolation of a highly active Photosystem II preparation from Synechocystis 6803 using a histidine-tagged mutant of CP 47. Biochim. Biophys. Acta 1998, 1409, 50-57. [CrossRef]

55. Ichihara, K.; Shibahara, A.; Yamamoto, K.; Nakayama, T. An improved method for rapid analysis of the fatty acids of glycerolipids. Lipids 1996, 31, 535-539. [CrossRef] [PubMed] 